\title{
Current Stage and Future Perspective of Stem Cell Therapy in Ischemic Stroke
}

\section{Buga Ana-Maria ${ }^{1,2 *}$, Albu Carmen ${ }^{2}$ and Tudorica Valerica ${ }^{2}$}

${ }^{1}$ Department of Biochemistry, University of Medicine, and Pharmacy of Craiova, Romania

${ }^{2}$ Department of Neurology, University of Medicine, and Pharmacy of Craiova, Romania

\begin{abstract}
Despite of high research efforts, ischemic stroke is the leading cause of adult disability worldwide, with enormous social and economic impact. To decrease the devastating impact of ischemic stroke on society, the researchers continue to seek strategies to achieve better functional recovery in stroke victims. This article reviews in detail the actual stage of research effort to develop new strategies in stem cells field, as well as stem cells delivery time course in closed relation with delivery route, stem cells origin, and the local microenvironment. In addition, ischemic stroke occurs in older people with comorbidities that may limit benefit and many preclinical studies did not take into account this. However, sustained research funding is mandatory to allow neuroscientist to develop and test new ways to improve the economic impact of stroke consequences on society.
\end{abstract}

Keywords: Ischemic stroke; Stem cell therapy; Comorbidities; Aged brain

\section{Introduction}

Stroke is the leading cause of long term-morbidity in aged people, but effective therapies still need to be developed. Stroke treatment design should cover all stages of the ischemic cascade, starting with the primary injury until the tissue regeneration and repair stage. Cerebral ischemia occur when the blood supply is decreased or interupted in the brain. Primary insult of the brain tissue is caused by deprivation of oxygen and glucose that are essential for neuronal cells to work and survive, and then continue with excitotoxicity phenomenon caused by glutamate release and calcium-dependent mitochondrial disfunction followed by DNA degradation and neuronal cell death.

Free radicals are other molecules that contribute to tissue destruction. Irreversible cell death occurs rapidly in the "core" of lesioned aria and progress faster in the adjacent area in the absence of a rapid intervention. This stage decides the fate of viable neurovascular unit cells to death or neurorepair and also, the fate of grafted stem cells. However, the only approved FDA drug, aimed to restore the blood flow, is tissue plasminogen activator (rt-PA). rt-PA wich has a limited time window (first 6 hours) and an increased risk of hemorrhagic complication [1].

With the development of the Stem Cell (SC) field, regenerative medicine has gained new perspectives in areas that lack treatment options, such as Cerebrovascular Diseases (CVD) including stroke. Research is focused on new promising therapy about stem cells transplantation and endogenous progenitor stem cell stimulation in order to promote brain repair after lession. This new perspective increase expectation that we can now make progress and develop an effective therapy to be used after recombinant tissue plasminogen activator (rt-PA) or endovascular intervention. However, the cellular and molecular events underlying this mechanism are still elusive.

\section{Aging and Basal Functional Status as Key Factors in Cerebral Ischemia}

Aging is a critical non-modifiable factor in the development of brain diseases especially in ischemic stroke. Different cellular and molecular changes alter the structure and function of the brain during the aging process [2]. Studies showed that aging process is associated with structural and cellular functional changes not only in the brain function, but also in metabolic pathways. Aging could also significantly affect the microenvironment of the brain in absence of diseases.

Studies before showed that neuronal functions could be impaired by aging due to increased oxidative damage, reduced metabolic activity, impaired energy metabolism and protein aggregation. Aged brain display a decreased endogenous neurogenesis, decreased growth factor production (vascular endothelial growth factor; brain-derived neurotrophic factor and insulin-like growth factor-1) [3]. However, the receptivity to stem cell transplants in aging microenvironment brain needs to be optimised.

\section{Stem Cells Therapy for Cerebral Ischemia in Preclinical Studies}

Recent advances in stem cell research in experimental studies have shown that the exogenous administration of neural stem cells (NSCs) or endogenous NSCs stimulation are able to improve post-stroke remodelling of the brain, even in aged people. We have previously shown that aging brain can activate repair pathway that are active in the young but this response is often delayed and not fully supported [4]. The aged brain cell therapy is a promising therapeutic strategy to promote brain tissue repair. In this regard, researchers are focused to identify the best candidate for stem cell therapy in stroke like Mesenchymal Stem Cells (MSCs) or Neural Stem Cells (NSCs) [5-8]. Of crucial importance when defining a novel therapeutic approach is the knowledge of mechanisms underlying the observed effects and to sustain these as long as long is needed for effective recovery. In this light, studies before report that the stem cell therapy can promote neurogenesis and axonal sprouting or

*Corresponding author: Ana-Maria Buga, Department of Biochemistry; University of Medicine and Pharmacy of Craiova Adress: Petru Rares Str, No 2, Craiova, Romania, Tel: +40351 443 500; E-mail: anamaria.buga@webmail.umfcv.ro

Received March 09, 2017; Accepted March 16, 2017; Published March 23, 2017

Citation: Ana-Maria B, Carmen A, Valerica T (2017) Current Stage and Future Perspective of Stem Cell Therapy in Ischemic Stroke. J Stem Cell Res Ther 7: 381. doi: 10.4172/2157-7633.1000381

Copyright: () 2017 Ana-Maria B, et al. This is an open-access article distributed under the terms of the Creative Commons Attribution License, which permits unrestricted use, distribution, and reproduction in any medium, provided the original author and source are credited. 
activate the restorative pathways by modulation of neuroinflammation or trophic factors production $[9,10]$. However, many studies using stem cells was assessed in young animals and these did not fully replicate the aged human condition including comorbidities.

\section{Neural Progenitor Cell Therapy in Ischemia-Reperfusion Injury}

In the acute period of stroke, successful reperfusion can also initiate the second stage of injury by inducing Blood-Brain-Barier (BBB) dysfunction, increasing pro-inflammatory molecules: inducible nitric oxide synthase (iNOS), Matrix Metalloproteinase (MMPs), Interleukin $1 \beta$ (IL1 $\beta)$, Tumor Necrosis Factor $\alpha(\mathrm{TNF} \alpha)$ and Reactive Oxygen Species (ROS) production. Despite of tremendous research efforts made to discover new neuroprotective strategies to limit acute injury to neuronal cells in ischemic area. Neuroprotection can be achieved by reducing the release of excitatory neurotransmitters in the ischemic area in order to enhance the neuronal survival $[11,12]$. However, several studies have reported neuroprotective strategies that are successful in animal stroke model, but these strategies failed in randomized placebocontrolled human studies. In this context, some questions must be addressed; it is useful in this stage any stem cell therapy? If so, what type of cell it is good to be used, which is the optimal delivery way and how they operate, are just a few questions that need an answer.

There are many opportunities for pharmacological intervention to attenuate the evolution of the cell death cascade. For the first time the neuroprotection was focused to save only neuronal cells. Today, our better understanding of the neurovascular unit concept has changed the focus from single cell to multi-cells protection in order to achieve optimal response following a cerebral ischemia $[13,14]$. Neurons are most vulnerable to ischemia, followed by endothelial cells, pericytes, microglia, and after that the astrocytes. In the first stage, post-ischemia increased Brain Blood Barrier (BBB) permeability leads to edema, peripheral immune cell infiltration, resident immune cells (microglia) activation and subsequently exaggerate injury in ischemic area of the brain. Endothelial Cells (ECs) are key players of the Blood Brain Barrier (BBB) that maintain "homodynamic" of the brain and low permeability. However, the peripheral inflammatory cells have a negative impact on neural stem cells and endogenous neurogenesis, especially in the aging brain where these processes are overactivated.

The recently discovered possibility to reprogram human adult somatic cells into the Induced Pluripotent Stem Cells (iPSCs) has added a promising tool to the panel of stem cells sources available for stem cell therapy. iPSCs possess the characteristics and potential assets of Embryonic Stem Cells (ESC), pluripotency and self-renewal, which allow the production of unlimited amounts of progenitors and precursor cells for all body cell types. In contrast with the impressive number of studies that deal with improvements of reprogramming techniques, pre-clinical data on therapeutic application of iPS remains limited. In keeping with the perspective of clinical application, the iPS research is focused on "safe" reprogramming processes in order to avoid permanent genetic modifications of donor cells and potential side effects after grafting. Many studies report that the Neuronal Progenitor Cells (NPCs) and Endothelial Progenitor Cells (EPCs) can be generated from human Inducible Pluripotent Stem Cells (iPSCs) [15-19]. Neuronal Progenitor Cells (NPCs) are able to differentiate into neurons, astrocytes, oligodendrocytes, and endothelial cells, which constitute most of the neurovascular unit cell types that are affected by ischemic insult.

In the early stage of stroke protection of Endothelial Cells (ECs) and BBB function should be an important strategy for reducing ischemia/ reperfusion injury, but there is still no clinical effective strategy. Studies using in vitro model of brain endothelial cell ischemia/reperfusin injury, characterized by decreased viability, increased apoptosis and cellular permeability, increased ROS production, reported that co-culture with EPCs or NPCs alone had beneficial effects on protecting ECs from initial damage by VEGF and BDNF paracrine-mediated activation of the PI3K/Akt signal pathway. VEGF and TrkB are reported to be the major modulators of endothelial survival [18-20]. These studies are performed in culture dish and if the cell response is the same in vivo in aged animals and humans, then we can attempt to use stem cell therapy, not only in a regenerative period but also in acute stage of stroke, prior to or following rtPA intervention.

Studies in vivo, using animal model reported that the transplanted human bone marrow Endothelial Progenitor Cells (hBMEPCs) can represent a new neurorestorative way for BBB repair in stroke [21]. On the other hand, intravenously transplanted NSCs at 24 hours after stroke onset can improve neurological function recovery without reduction of infarct volume. Interesting, the NSCs could migrate into the ischemic areas, displays a proliferative capacity and enhance the endogenous stem cells in the adult rat brain after stroke [22,23]. However, exogenous NSCs cells appear to have different mechanisms of action depending on delivery route. In this light, systemic delivery of NPCs in the acute phase (first 24h) of stroke in adult mice (11-13 weeks) has neuroprotective effect by preventing Blood-Brain-Barrier (BBB) damage, decrease matrix metalloprotease 9(MMP9) overexpression and Reactive Oxygen Species (ROS) [24].

\section{Neural Progenitor Cell Therapy in the Post-Acute Phase of Stroke}

Neural progenitor cells therapy has been reported in the last years as future therapy for functional recovery after stroke, but the mechanism that underlies NPCs-mediated neurorecovery is still under debate. Some issues remain to be solved:

i. To explain whether exogenous NPCs can modulate adaptative plasticity and structural/functional remodelling in the chronic phase of stroke;

ii. To understand the cellular and molecular mechanisms by which exogenous NPCs promote adaptative microenvironment changes and improve post-stroke recovery.

However, is still not clear if the NPCs contribute to stroke recovery in the postacute phase by:

i. Differentiation to functional neurons, astrocytes, glial cells or endothelial cells that are able to replace the damaged ones in aged specific environment;

ii. By releasing specific molecule in penumbra that can change the local aged microenvironment in order to promote functional recovery;

iii. Or by modulation of neuroinflammation in the subacute phase of stroke.

Recent studies have showed that grafted human iPSC cells can generate functional neurons that can send projections and receive synaptic input from neighbouring neurons, which lead to improvement of motor function even in aged animals $[10,25]$. NSCs mechanisms of action seems to be much complex than simply neuroreplacement. Other studies found that the NPCs delivery in subacute phase of stroke can promote adaptive plasticity by modulating the ischemia 
microenvironment and improves excitatory-inhibitory balance by upregulating glutamate transporter GLT1 in endogenous astrocytes [26]. However, these studies was perform in adult animals that are not affected by senescence and is still not clear if the response of the senescent brain will replicate the young one.

NPCs were also reported to increase angiogenesis and vasculogenesis in the chronic phase of stroke $[27,28]$. The mechanism of action seems to be multimodal, NPCs can modulate post-stroke angiogenesis in multiple ways:

i. By increasing endogenous levels of trophic factors and fibroblast growth factor (FGF) that could induce proliferation of existing vascular endothelial cells (angiogenesis) and new blood vessel formation from endogenous endothelial progenitors cells (vasculogenesis);

ii. By secreting local trophic factors that could promote angiogenesis/angiogenesis.

In animal model of cerebral ischemia associated with diabetes type 2, Bone Marrow Stromal Cells (BMSCs) significantly decreases inflammation and improve functional outcome after stroke by reducing the expression of proinflammatory factors like high-mobility group box 1 (HMGB1) and receptor for advanced glycation and products (RAGE) [29].

\section{Mesenchymal Stem Cells Transplantation in the Acute Phase of Stroke}

Mesenchymal Stem Cells (MSCs) proved to be one of the promising candidates for cell therapy in ischemic stroke. In this light, exogenous MSCs may inhibit endothelial dysfunction to suppress BBB damage and improve functional outcome. In the early phase of cerebral ischemia, exogenous MSCs after rtPA therapy promote early behavioural recovery [30].

The mechanism of action is that the delivery of cells in the acute phase decreases apoptosis in the penumbra and display a neuroprotective effect by local secretion of trophic factors. Apoptosis is decreased by diminishing Tumor Necrosis Factor Alpha (TNFa), Interleukin 6 and 1 beta (IL6; IL1 $\beta$ ) that are key factors in microglia induced-phagocytosis of death neurons, but can also promote phagocytosis of viable neurons. If microglia induced phagocytosis is beneficial for removing debris, it can be detrimental for exogenous stem cells and can limit the efficiency of stem cell therapy.

Wang and colleagues showed that the transplantation of BMSCs in the early phase of stroke (first $24 \mathrm{~h}$ ) can reduce the infarcted area and promote motor recovery in a dose-dependent manner. An explanation for this effect is that the exogenous BMSCs my limit macrophages/microglia activation and reduce infiltration of gamma delta $\mathrm{T}(\gamma \delta \mathrm{T})$ cells [31].

Studies using type 2 diabetic rats showed that exogenous BMSCs delivery was correlated with better functional recovery by decreasing BBB leakage and overexpression of Ang1 and Tie2 genes [32]. Only few studies takes into account comorbidities associated with stroke in the elderly.

Our studies before showed that the combination of G-CSF and BMSCs increased new blood vessel formation in the infarct core generating an "regeneration islet" [33]. However, BMSCs therapy needs further investigation.

\section{Stem Cell Therapy in Translational and Clinical Studies}

The two pioneering clinical trials using neural precursor cells (NPC) was performed. The most recent one using NPCs in the aged people in the chronic stage (6-60 month after stroke) reported an improved neurological outcome and no adverse effect related to cells administration. Interestingly, they reported the negative effect due to comorbidities [34]. The second one was performed using human neuronal cells and report the safety and feasibility of neuron transplantation for patients with motor stroke [35]. Other clinical trials using bone marrow derived stem cell (BMSC) in stroke have shown the feasibility and safety of the approach [36-39]. Moniche et al. showed that the BMSC in subacute Middle Cerebral Artery (MCA) stroke patients could induce changes in serum levels of GranulocyteMacrophage Colony-Stimulating Factor (GM-CSF), platelet-derived growth factor-BB (PDGF-BB), and matrix metalloproteinases 2 (MMP2), which could induce an improved functional outcomes [40].

Clinical trials reported a discrepancy compare with preclinical studies regarding the relevance of cell dose. In preclinical studies, no relevancy was reported for dose dependent functional outcome in NSCs therapy, but some clinical trials reported a better functional outcome correlated with increased dose of NSCs [41]. However, clinical trials were performed in the subacute phase and reported that the single cell dose not sufficient to improve the functional outcome (Table 1).

Clinical investigation using stem cells in ischemic stroke patients are currently underway. 115 clinical trials using stem cells are ongoing now (http://www.ClinicalTrials.gov/). Our data collection from 37 registered clinical trials using stem cell therapy in stroke (with ClinicalTrials.gov ID number) show that the majority of these (42\%) are in the phase 2 stage and six of them are currently completed (Figure 1). The available results from 2 completed clinical trial showed that intravenous delivery of Bone Marrow Mononuclear Stem Cell (BMSCs) is safe, but no beneficial effect was obtained in functional recovery with this method $[38,39]$. Other clinical trial using intrathecal transplantation of Bone Marrow Mononuclear Stem Cell (BMSCs) reported no adverse effects and improved functional recovery [42]. However, this study is limited by small sample size and heterogeneous group. Some clinical trials are carrying at the moment in order to test first trial to explore efficacy of different doses and delivery route of stem cells in stroke [41,43]. Clinical trials that reported an improved clinical outcome after stem cell therapy are summarized in Table 2 .

Despite of clinical trials that report stem cell therapy to be without side effect, in this stage the risk and advantages of such therapy needs to be well established. The major risk factor is associated with capacity of undifferentiated cells to form tumors [44]. Some isolated cases of tumor formation was observed in patients after stem cells transplantation $[45,46]$. If this potential can be generated by the type of stem cell or by delivery number of cells should be further established. However, other clinical trials that search for safety and afficacy of different stem cells are ongoing now $[41,47]$. Other clinical trials that were completed until now did not report tumor formation in humans after stem cell delivery [40].

Other potential risk of stem cells therapy is due to stem cells immunogenicity. In this light clinical trials was performed using autologous stem cells that are generally accepted to be with no risks for rejection [48].

Preclinical studies showed that one potential risk involves migration, and engraftment of transplanted cells. Intravenous and intra-arterial route of delivery has the disadvantage that majority of cells are grafted to other organs like lung, liver or spleen and only some cells are founded in the ischemic penumbra [49]. All these potential risk still need to be investigating in order to optimise stem cell therapy in stroke. 
Citation: Ana-Maria B, Carmen A, Valerica T (2017) Current Stage and Future Perspective of Stem Cell Therapy in Ischemic Stroke. J Stem Cell Res Ther 7: 381. doi: 10.4172/2157-7633.1000381

Page 4 of 7

\begin{tabular}{|c|c|c|c|c|c|}
\hline Cell Type & Experimental/clinical study & Acute/chronic & Route of phase delivery & Age/comorbidities & Reference \\
\hline NSCs & rats & Acute phase (0-1day poststroke) & intracerebral & Old rats $(24 \mathrm{Mo}) / \mathrm{No}$ & [28] \\
\hline NSCs & rats & Subacute phase (2-3 weeks poststroke) & intracerebral & Old rats $(24 \mathrm{Mo}) / \mathrm{No}$ & {$[76,77]$} \\
\hline iPSCs & rats & Subacute phase (2days poststroke) & intracerebral & Old rats $(24 \mathrm{Mo}) / \mathrm{No}$ & [10] \\
\hline MSCs & rats & Acute phase & intracerebral & Old rats $(24 \mathrm{Mo}) / \mathrm{No}$ & [78] \\
\hline BM-MNCs & Clinical trial & Subacute phase (1-3dayspoststroke) & Autologous & $18-80$ years old/No & {$[36]$} \\
\hline BM-MNCs & Clinical trial & Subacute phase (3-7 days) & Autologous intraarterial & Adult/No & [37] \\
\hline BM-MNCs & Clinical trial & Subacute phase (5-7 days) & $\begin{array}{c}\text { Autologous } \\
\text { intraparenchymal }\end{array}$ & Adult/No & [79] \\
\hline MSCs & Clinical trial & Chronic phase (3month) & Autologous intravenous & Adult/No & [80-82] \\
\hline
\end{tabular}

Table 1: Stem cell therapy in experimental models vs. clinical trials.

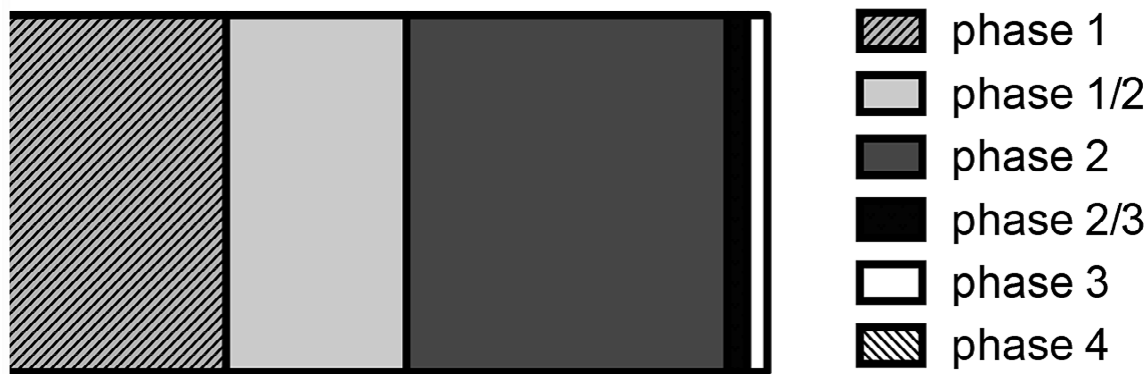

Figure 1: Registered clinical trial using Stem cell therapy in stroke in function of clinical phase

\begin{tabular}{|c|c|c|c|c|c|}
\hline Cell type & Study design & Infarct stage & Delivery route & Clinical grade & Reference \\
\hline \multirow{4}{*}{ BM-MNCs } & Treatment $\mathrm{N}=20$ & Subacute phase (3-7 days) & Autologous intraarterial $/ 2.2 \times 10^{8} \mathrm{cells} / \mathrm{Kg}$ & Good clinical outcome; mRS * $\leq 2(40 \%)$ & {$[37]$} \\
\hline & Treatment $\mathrm{N}=10$ & acute phase ( $24-72$ hours) & Autologous inravenous $/ 1 \times 10^{6}$ cells $/ \mathrm{Kg}$ & $\begin{array}{l}\text { NIHSS }{ }^{* *} \text { improved by } 13 \text { to } 3 \text { at } 6 \text { month; } 1 \text { point } \\
\text { improvement in mRS; Bartel } \geq \text { index } 9070 \% \text { ) }\end{array}$ & {$[36]$} \\
\hline & $\begin{array}{l}\text { Treatment } \mathrm{N}=60 \\
\text { Control } \mathrm{N}=40\end{array}$ & $\begin{array}{l}\text { Subacute phase } \\
6 \text { days post stroke }\end{array}$ & intracerebral & Improved NIHSS and Bartel index (86.7\%) & [79] \\
\hline & Treatment =24 & Chronic Stage & Intratechal $/ 16 \times 10$ cells $/ \mathrm{Kg}$ & Improved functional independe nce & [42] \\
\hline \multirow[t]{2}{*}{ BM-MSCs } & Treatment $\mathrm{N}=16$ & Subacute stage & Autologous intravenous/81 $\times 10$ & Increased mRS & [82] \\
\hline & Treatment $\mathrm{N}=12$ & Chronic phase & Autologous intravenous/81 $\times 10$ & Improved NIHSS & [81] \\
\hline
\end{tabular}

*modified Rankin Scale (mRS); **National Institutes of Health Stroke Scale (NIHSS)

Table 2: Clinical trials of optimum stem cell therapy in ischemic stroke patient

\section{Epigenomic Basis in Stroke}

The epigenetics field opens new perspectives in terms of understanding the response of brain to injury. Also, epigenetics is a key that open the door insight into the cellular and molecular bases of genomic programs that promote brain plasticity after stem cell therapy especially in the elderly. DNA methylation, histone code modifications, non-protein-coding RNAs (ncRNAs), and RNA editing are involved in brain development, brain senescence and brain plasticity [50,51]. DNA methylation is increased in the acute phase of stroke during the ischemia reperfusion injury. In preclinical studies was showed that the methylation process decrease the neuroprotective genes and promote neuronal death $[52,53]$.

Previously observations have indicated that the global levels of DNA methylation in neural cells was altered by ischemia or oxidative stress and the inhibitors of DNA methyltransferases (DNMTs) are able to alleviate the neural injury that caused by ischemia or oxidative stress [52,54]. Also, in the chronic phase, DNA methylation is involved in neurorepair processes such as neurogenesis and synaptic remodelling after stroke and can be modulated through epigenetic control of expression pathways $[55,56]$.
Apart from DNA methylation, ischemia stroke also leads to the dysfunction of some histone modifiers in astrocytes in rat models [57]. Interestingly, as recent studies demonstrated that inhibition of histone methyltransferases SUV39H1 and G9a is able to protection the neurons in the model of cerebral ischemia [58] and these methyltransferases also play a role in the maintenance of DNA methylation [59].

Also, micro RNAs (miRNAs) that play an important role in developmental period of nervous system by promoting angiogenesis, neurogenesis and oligodendrogenesis are altered after stroke [60,61]. Studies in vivo, showed that the modulation of miRNAs can promote angiogenesis with $\mathrm{BBB}$ damage prevention [60,62]. By targeting pathway like Sonic Hedgehog (Shh) or JAG-Notch signalling pathway the neurogenesis can be increased after stroke $[62,63]$.

Preclinical studies reported also an increased oligodendrogenesis after miRNAs by modulation of target genes like Irak1 in oligodendrocyte progenitor cells (OPC) that decrease OPC apoptosis [64]. In vitro, studies before suggest that the mechanisms of improved oligodendrogenesis after miRNAs administration by increase serum response factor (SRF) in OPC [65].

In clinical studies, miRNAs was identified as potential biomarker that can predict the stroke severity in young people [66]. 


\section{Discussion}

Exogenous NSCs transplanted in the early stage after stroke in adult animals retain proliferative capacity and enhance endogenous stem cell proliferation that is beneficial for stroke recovery. These studies are perform using adult animals that are not yet affected by senescence. However, if the aging brain response is similar to young one, exogenous administration of NSCs should improve the functional recovery in aged people. However, our previous studies showed that the aging brain's response to injury is often delayed and unsustainable even in the absence of comorbidities like diabetes.

Aged animals develop larger infarcts compare with young one and functional outcome was worse in age rats $[4,67]$. Further studies are necessary to establish the exogenous NSCs behaviour in the aged organisms with or without comorbidities. These studies are crucial to establish when these interventions are beneficial and when not.

Based on animal models of stroke it is not clear which route of delivery increase the efficiency of stem cell therapy [68,69]. Some, preclinical studies have indicated that only small number of cells reaching the ischemic brain after systemic administration, many of these leads to cell arrest in organs like the lungs, liver or spleen [70]. Intra-arterial route of delivery of MSCs, but not Bone Marrow Mononuclear Cells (BM-MNCs), was associated with new ischemic attack and increased mortality in animal model. This may be due to the transplanted cells size $[71,72]$.

Doeppner et al. showed that the different delivery route display different mechanisms of action. According with this study in the first stage of stroke when we need to prevent BBB leakage and ROS formation systemic transplantation of NPCs can be the best route. Later in the subacute stage, when we need to enhance endogenous neurogenesis and promote long-term neuroprotection intracerebral transplantation seems to be the best route of delivery, which is followed by increased production of growth factors [24].

The mechanisms by which stem cells may sustain infarcted brain tissue seem related more to the ability of stem cells to release neuroprotective factors than to their capacity to replace damaged cells. Studies before suggest that the stem cells promote neurorecovery by multimodal mechanisms [73]. In function of what we need to modulate the correct timing is crucial for therapeutic strategy. As long as systemic delivery of different type of stem cells in the acute phase display neuroprotective effect in animal model, this less invasive route of delivery should be further studied in translational stroke studies in aged people. However, many of these studies in vivo were performed in subacute stage of cerebral ischemia and they did not use aged animals.

Significant differences exist in the aged compared with young animal response after injury. We showed before that the ischemic injury rapidly progress to brain infarction in the aged brain, endogenous neurogenesis is decreased and the neurological recovery is delayed. Agerelated comorbidities, like diabetes, hypertension or hyperlipidaemia, may result compromise structural brain reorganisation and can decrease efficiency of cell-based. These age-related aspects may be key factors in the clinical translation of tissue regeneration interventions.

The optimal time window for stem cell therapy after stroke is still not well established. This aspect is crucial if we take in account that the brain environment changes dramatically over time after ischemic attack. In the acute phase there is an increase in excitotoxicity, BBB leakage, and reactive oxygen species release. This is followed by an inflammatory response and cell death, which, in the penumbra, can extend up to several weeks. Next phase, tissue reorganization and regeneration, take place over several month and depend on the acute phase interventions. To know the mechanism of different type of stem cells is crucial to decide optimal time of delivery. Some strategies will be considered:

i) Short term neuroprotection;

ii) Long-term neuroprotection

iii) Endogenous regeneration mechanisms (angio/neurogenesis; aaptative plasticity; structural and functional remodelling). However, the late stages are strongly influenced by the earliest interventions.

In addition, epigenetics field is a novel approach for stroke recovery with promising future. Understanding the patterns of SUV39H1 and G9a associated H3K9 methylation as well as DNA methylation might create a novel direction for revealing the epigenetic mechanisms that involved in initiation and development of ischemia stroke in patients. Aging process itself is associated with DNA methylation and can predict and increased risk of age-related diseases [74,75]. However, majority of stroke studies was performed in young organisms but we should take in account the baseline epigenetic changes associated with brain senescence in order to predict successful clinical translation of epigenetic modulation after stroke in the elderly.

\section{Conclusion}

Different optimizations strategy increase the role of stem cells in key biological pathways and promote the therapeutic efficacy of stem cells in stroke. Future investigations should focus on some crucial aspects to reach functional improvement in clinical trials:

iv) Understanding how exogenous stem cells and the aged brain affects each other;

v) Understanding how comorbidities and exogenous stem cells affects each other;

vi) Characterize the basal functional status according with age and comorbidities and the response of the brain according with these conditions;

vii) Genetic modifications and drug combinations;

viii) Optimal timing, type and doses for stem cell transplantation according with each stage of stroke Progression;

ix) Understanding the patterns of epigenetic mechanisms that involved in initiation and development of ischemia stroke in patients is crucial for development of new therapeutic strategies that are able to promote neuroprotection and neurorecovery after stroke.

\section{Competing Interests}

The authors declare that they have no competing interests

\section{Acknowledgement}

This work was supported by a grant of the Romanian National Authority for Scientific Research and Innovation, CNCS - UEFISCDI, project number PN-II-RUTE-2014-4-0705.

\section{References}

1. Ning M, Sarracino DA, Buonanno FS, Krastins B, Chou S, et al. (2010) Proteomic protease substrate profiling of tPA treatment in acute ischemic stroke patients: a step toward individualizing thrombolytic therapy at the bedside. Translat Stroke Res 1: 268-275. [PubMed] 
2. Chowdhury MH, Nagai A, Bokura H, Nakamura E, Kobayashi S, et al. (2011) Age-related changes in white matter lesions, hippocampal atrophy, and cerebral microbleeds in healthy subjects without major cerebrovascular risk factors. J Stroke Cerebrovasc Dis 20: 302-309. [PubMed]

3. Tripathy D, Sanchez A, Yin X, Martinez J, Grammas P (2012) Age-related decrease in cerebrovascular-derived neuroprotective proteins: effect of acetaminophen. Microvasc Res 84: 278-285. [PubMed]

4. Buga AM, Sascau M, Pisoschi C, Herndon JG, Kessler C, et al. (2008) The genomic response of the ipsilateral and contralateral cortex to stroke in aged rats. J Cell Mol Med 12: 2731-2753. [PubMed]

5. Pittenger MF, Mackay AM, Beck SC, Jaiswal RK, Douglas R, et al. (1999) Multilineage potential of adult human mesenchymal stem cells. Science 284 143-147. [PubMed]

6. Caplan Al, Correa D (2011) The MSC: an injury drugstore. Cell Stem Cell 9: 11-15. [PubMed]

7. Borlongan CV, Lind JG, Dillon-Carter O, Yu G, Hadman M, et al. (2004) Bone marrow grafts restore cerebral blood flow and blood brain barrier in stroke rats. Brain Res 1010: 108-116. [PubMed]

8. Mahmood A, Lu D, Wang L, Chopp M (2002) Intracerebral transplantation of marrow stromal cells cultured with neurotrophic factors promotes functional recovery in adult rats subjected to traumatic brain injury. J Neurotrauma 19 1609-1617. [PubMed]

9. Buga AM, Scheibe J, Moller K, Ciobanu O, Posel C, et al. (2015) Granulocyte colony-stimulating factor and bone marrow mononuclear cells for stroke treatment in the aged brain. Curr Neurovasc Res 12: 155-162. [PubMed]

10. Tatarishvili J, Oki K, Monni E, Koch P, Memanishvili T, et al. (2014) Human induced pluripotent stem cells improve recovery in stroke-injured aged rats. Restor Neurol Neurosci 32: 547-558. [PubMed]

11. Onwuekwe I, Ezeala-Adikaibe B (2012) Ischemic Stroke and Neuroprotection. Ann Med Health Sci Res 2: 186-190. [PubMed]

12. Zhou X, Hollern D, Liao J, Andrechek E, Wang H (2013) NMDA receptormediated excitotoxicity depends on the coactivation of synaptic and extrasynaptic receptors. Cell Death Dis 4: e560. [PubMed]

13. Xing C, Hayakawa K, Lok J, Arai K, Lo EH (2012) Injury and repair in the neurovascular unit. Neurol Res 34: 325-330. [PubMed]

14. Lok J, Wang XS, Xing CH, Maki TK, Wu LM, et al. (2015) Targeting the neurovascular unit in brain trauma. CNS Neurosci Ther 21: 304-308. [PubMed]

15. Takahashi K, Yamanaka $S$ (2006) Induction of pluripotent stem cells from mouse embryonic and adult fibroblast cultures by defined factors. Cell 126 663-676. [PubMed]

16. Takahashi K, Tanabe K, Ohnuki M, Narita M, Ichisaka T, et al. (2007) Induction of pluripotent stem cells from adult human fibroblasts by defined factors. Cell 131:861-72. [PubMed]

17. Yu J, Vodyanik MA, Smuga-Otto K, Antosiewicz-Bourget J, Frane JL et al. (2007) Induced pluripotent stem cell lines derived from human somatic cells. Science 318: 1917-1920. [PubMed]

18. Wang J, Chen Y, Yang Y, Xiao X, Chen S, et al. (2016) Endothelial progenito cells and neural progenitor cells synergistically protect cerebral endothelia cells from Hypoxia/reoxygenation-induced injury via activating the PI3K/Akt pathway. Mol Brain 9: 12. [PubMed]

19. Kim H, Li Q, Hempstead BL, Madri JA (2004) Paracrine and autocrine functions of brain-derived neurotrophic factor (BDNF) and nerve growth factor (NGF) in brain-derived endothelial cells. J Biol Chem 279: 33538-33546. [PubMed]

20. Wang J, Chen S, Ma X, Cheng C, Xiao X, et al. (2013) Effects of Endothelia Progenitor Cell-Derived Microvesicles on Hypoxia/Reoxygenation-Induced Endothelial Dysfunction and Apoptosis. Oxid Med Cell Longev 2013: 572729. [PubMed]

21. Garbuzova-Davis S, Haller E, Lin R, Borlongan CV (2017) Intravenously Transplanted Human Bone Marrow Endothelial Progenitor Cells Engraft Within Brain Capillaries, Preserve Mitochondrial Morphology, and Display Pinocytotic Activity Towards BBB Repair in Ischemic Stroke Rats. Stem Cells [PubMed]

22. Cheng $Y$, Zhang J, Deng L, Johnson NR, Yu X, et al. (2015) Intravenously delivered neural stem cells migrate into ischemic brain, differentiate and improve functional recovery after transient ischemic stroke in adult rats. Int $J$ Clin Exp Pathol 8: 2928-2936. [PubMed]
23. Song M, Kim YJ, Kim YH, Roh J, Kim SU, et al. (2011) Effects of duplicate administration of human neural stem cell after focal cerebral ischemia in the rat Int J Neurosci 121: 457-461. [PubMed]

24. Doeppner TR, Ewert TAS, Tönges L, Herz J, Zechariah A, et al. (2012) Transduction of Neural Precursor Cells with TAT-Heat Shock Protein 70 Chaperone: Therapeutic Potential Against Ischemic Stroke after Intrastriatal and Systemic Transplantation. Stem Cells 30: 1297-1310. [PubMed]

25. Oki K, Tatarishvili J, Wood J, Koch P, Wattananit S, et al. (2012) Humaninduced pluripotent stem cells form functional neurons and improve recovery after grafting in stroke-damaged brain. Stem Cells 30: 1120-1133. [PubMed]

26. Bacigaluppi M, Russo GL, Peruzzotti-Jametti L, Rossi S, Sandrone S, et al. (2016) Neural Stem Cell Transplantation Induces Stroke Recovery by Upregulating Glutamate Transporter GLT-1 in Astrocytes. J Neurosci 36 10529-10544. [PubMed]

27. Zhang J, Chopp M (2013) Cell-based therapy for ischemic stroke. Expert Opin Biol Ther 13: 1229-1240. [PubMed]

28. Tang Y, Wang J, Lin X, Wang L, Shao B, et al. (2014) Neural stem cell protects aged rat brain from ischemia-reperfusion injury through neurogenesis and angiogenesis. J Cereb Blood Flow Metab 34: 1138-1147. [PubMed]

29. Hu J, Liu B, Zhao Q, Jin P, Hua F, et al. (2016) Bone marrow stromal cells inhibits HMGB1-mediated inflammation after stroke in type 2 diabetic rats. Neuroscience 324: 11-19. [PubMed]

30. Nakazaki M, Sasaki M, Kataoka-Sasaki Y, Oka S, Namioka T, et al. (2017) Intravenous infusion of mesenchymal stem cells inhibits intracranial hemorrhage after recombinant tissue plasminogen activator therapy for transient middle cerebral artery occlusion in rats. J Neurosurg 6: 1-10. [PubMed]

31. Wang LQ, Lin ZZ, Zhang HX, Shao B, Xiao L, et al. (2014) Timing and dose regimens of marrow mesenchymal stem cell transplantation affect the outcomes and neuroinflammatory response after ischemic stroke. CNS Neurosci Ther 20 : 317-326. [PubMed]

32. Xiang J, Hu J, Shen T, Liu B, Hua F, et al. (2017) Bone marrow mesenchymal stem cells-conditioned medium enhances vascular remodeling after stroke in type 2 diabetic rats. Neurosci Lett 644: 62-66. [PubMed]

33. Buga AM, Margaritescu C, Scholz CJ, Radu E, Zelenak C, et al. (2014) Transcriptomics of post-stroke angiogenesis in the aged brain. Front Aging Neurosci 6: 44. [PubMed]

34. Kalladka D, Sinden J, Pollock K, Haig C, McLean J, et al. (2016) Human neura stem cells in patients with chronic ischaemic stroke (PISCES): a phase 1, firstin-man study. Lancet 388: 787-796. [PubMed]

35. Kondziolka D, Steinberg GK, Wechsler L, Meltzer CC, Elder E, et al. (2005) Neurotransplantation for patients with subcortical motor stroke: a phase 2 randomized trial. J Neurosurg 103: 38-45. [PubMed]

36. Savitz SI, Misra V, Kasam M, Juneja H, Cox CS Jr, et al. (2011) Intravenous autologous bone marrow mononuclear cells for ischemic stroke. Ann Neurol 70: 59-69. [PubMed]

37. Friedrich MA, Martins MP, Araújo MD, Klamt C, Vedolin L, et al. (2012) Intraarterial infusion of autologous bone marrow mononuclear cells in patients with moderate to severe middle cerebral artery acute ischemic stroke. Cell Transplant 21: S13-S21. [PubMed]

38. Prasad K, Mohanty S, Bhatia R, Srivastava MV, Garg A, et al. (2012) Autologous intravenous bone marrow mononuclear cell therapy for patients with subacute ischaemic stroke: A pilot study. Indian J Med Res 136: 221-228. [PubMed]

39. Prasad K, Sharma A, Garg A, Mohanty S, Bhatnagar S, et al. (2014) Intravenous autologous bone marrow mononuclear stem cell therapy for ischemic stroke: a multicentric, randomized trial. Stroke 45: 3618-3624. [PubMed]

40. Moniche F, Montaner J, Gonzalez-Marcos JR, Carmona M, Piñero P, et al (2014) Intra-Arterial Bone Marrow Mononuclear Cell Transplantation Correlates With GM-CSF, PDGF-BB, and MMP-2 Serum Levels in Stroke Patients: Results From a Clinical Trial. Cell Transplant 23: 57-64 [PubMed]

41. Moniche F, Escudero I, Zapata-Arriaza E, Usero-Ruiz M, Prieto-León M, et al. (2015) Intra-arterial bone marrow mononuclear cells (BM-MNCs) transplantation in acute ischemic stroke (IBIS trial): protocol of a phase II, randomized, dosefinding, controlled multicenter trial. Int J Stroke 10: 1149-1152.

42. Sharma A, Sane H, Gokulchandran N, Khopkar D, Paranjape A, et al. (2014) Autologous Bone Marrow Mononuclear Cells Intrathecal Transplantation in Chronic Stroke. Stroke Res Treatment. 
Citation: Ana-Maria B, Carmen A, Valerica T (2017) Current Stage and Future Perspective of Stem Cell Therapy in Ischemic Stroke. J Stem Cell Res Ther 7: 381. doi: 10.4172/2157-7633.1000381

43. Hess DC, Sila CA, Furlan AJ, Wechsler LR, Switzer JA, et al. (2014) A doubleblind placebo-controlled clinical evaluation of MultiStem for the treatment of ischemic stroke. Int J Stroke 9: 381-386. [PubMed]

44. Lee AS, Tang C, Cao F, Xie X, van der Bogt K, et al. (2009) Effects of cell number on teratoma formation by human embryonic stem cells. Cell Cycle 8 : 2608-2612. [PubMed]

45. Dlouhy BJ, Awe O, Rao RC, Kirby PA, Hitchon PW (2014) Autograft-derived spinal cord mass following olfactory mucosal cell transplantation in a spinal cord injury patient: Case report. J Neurosurg Spine 21: 618-622. [PubMed]

46. Amariglio N, Hirshberg A, Scheithauer BW, Cohen Y, Loewenthal R, et al. (2009) Donor-derived brain tumor following neural stem cell transplantation in an ataxia telangiectasia patient. PLoS Med 6: e1000029. [PubMed]

47. Steinberg GK, Kondziolka D, Wechsler LR, Lunsford LD, Coburn ML (2016) Clinical Outcomes of Transplanted Modified Bone Marrow-Derived Mesenchymal Stem Cells in Stroke: A Phase 1/2a Study. Stroke 47: 18171824.

48. Morizane A, Doi D, Kikuchi T, Okita K, Hotta A, et al. (2013) Direct comparison of autologous and allogeneic transplantation of iPSC derived neural cells in the brain of a non-human primate. Stem Cell Rep 1: 283-292. [PubMed]

49. Acosta SA, Tajiri N, Hoover J, Kaneko Y, Borlongan CV (2015) Intravenous Bone Marrow Stem Cell Grafts Preferentially Migrate to Spleen and Abrogate Chronic Inflammation in Stroke. J Cereb Circ 46: 2616-2627.

50. Teng H, Zhang ZG, Wang L, Zhang RL, Zhang L, et al. (2008) Coupling of angiogenesis and neurogenesis in cultured endothelial cells and neural progenitor cells after stroke. J Cereb Blood Flow Metab 28: 764-771. [PubMed]

51. Qureshi IA, Mehler MF (2011) Advances in epigenetics and epigenomics for neurodegenerative diseases. Curr Neurol Neurosci Rep 11: 464-473. [PubMed]

52. Endres M, Fan G, Meisel A, Dirnagl U, Jaenisch R (2001) Effects of cerebral ischemia in mice lacking DNA methyltransferase 1 in post-mitotic neurons. Neuroreport 12: 3763-3766. [PubMed]

53. Dock H, Theodorsson A, Theodorsson E (2015) DNA Methylation Inhibitor Zebularine Confers Stroke Protection in Ischemic Rats. Transl Stroke Res 6: 296-300. [PubMed]

54. Endres M, Meisel A, Biniszkiewicz D, Namura S, Prass K et al. (2000) DNA methyltransferase contributes to delayed ischemic brain injury. J Neurosci 20: 3175-3181. [PubMed]

55. Jung BP, Zhang G, Ho W, Francis J, Eubanks JH (2002) Transient forebrain ischemia alters the mrna expression of methyl DNA-binding factors in the adult rat hippocampus. Neuroscience 115: 515-524. [PubMed]

56. Smrt RD, Eaves-Egenes J, Barkho BZ, Santistevan NJ, Zhao C, et al. (2007) Mecp2 deficiency leads to delayed maturation and altered gene expression in hippocampal neurons. Neurobiol Dis 27: 77-89. [PubMed]

57. Chisholm NC, Henderson ML, Selvamani A, Park MJ, Dindot S, et al. (2015) Histone methylation patterns in astrocytes are influenced by age following ischemia. Epigenetics 10: 142-152. [PubMed]

58. Schweizer S, Harms C, Lerch H, Flynn J, Hecht J, et al. (2015) Inhibition of histone methyltransferases SUV39H1 and G9a leads to neuroprotection in an in vitro model of cerebral ischemia. J Cereb Blood Flow Metab 35: 1640-1647. [PubMed]

59. Zhang T, Termanis A, Özkan B, Bao XX, Culley J, et al. (2016) G9a/GLP Complex Maintains Imprinted DNA Methylation in Embryonic Stem Cells. Cell Rep 15: 77-85. [PubMed]

60. Teng H, Chopp M, Liu X, Wang X, Chen C, et al. (2012) Stroke alters mirna expression profiles in cerebral endothelial cells. In Proceedings of the Annual Society for Neuroscience Meeting, New Orleans, LA, USA.

61. Kassis H, Shehadah A, Chopp M, Zhang ZG (2017) Epigenetics in Stroke Recovery. Genes (Basel) 8. [PubMed]

62. Liu XS, Chopp M, Wang XL, Zhang L, Hozeska-Solgot A, et al. (2013) Microrna-17-92 cluster mediates the proliferation and survival of neural progenitor cells after stroke. J Biol Chem 288: 12478-12488. [PubMed]

63. Liu XS, Chopp M, Zhang RL, Tao T, Wang XL et al. (2011) Microrna profiling in subventricular zone after stroke: Mir-124a regulates proliferation of neural progenitor cells through notch signaling pathway. PLoS ONE 6: e23461. [PubMed]
64. Liu Y, Zheng Y, Li S, Xue H, Schmitt K, et al. (2017) Human neural progenitors derived from integration-free iPSCs for SCI therapy. Stem Cell Res 19: 55-64. [PubMed]

65. Buller B, Chopp M, Ueno Y, Zhang L, Zhang RL, et al. (2012) Regulation of serum response factor by miRNA-200 and miRNA-9 modulates oligodendrocyte progenitor cell differentiation. Glia 60: 1906-1914. [PubMed]

66. Vijayan M, Reddy PH (2016) Peripheral biomarkers of stroke: Focus on circulatory microRNAs. Biochim Biophys Acta 1862: 1984-1993. [PubMed]

67. Buga AM, Scholz CJ, Kumar S, Herndon JG, Alexandru D, et al. (2012) Identification of new therapeutic targets by genome-wide analysis of gene expression in the ipsilateral cortex of aged rats after stroke. PLoS One 7: e50985. [PubMed]

68. Vu Q, Xie K, Eckert M, Zhao W, Cramer SC (2014) Meta-analysis of preclinical studies of mesenchymal stromal cells for ischemic stroke. Neurology 82: 1277 1286. [PubMed]

69. Chen L, Zhang G, Khan AA, Guo X, Gu Y (2016) Clinical Efficacy and MetaAnalysis of Stem Cell Therapies for Patients with Brain Ischemia. Stem Cells Int 2016: 6129579. [PubMed]

70. Yang B, Strong R, Sharma S, Brenneman M, Mallikarjunarao K, et al. (2011) Therapeutic time window and dose response of autologous bone marrow mononuclear cells for ischemic stroke. J Neurosci Res 89: 833-839. [PubMed]

71. Walczak P, Zhang J, Gilad AA, Kedziorek DA, Ruiz-Cabello J, et al. (2008) Dual-modality monitoring of targeted intraarterial delivery of mesenchymal stem cells after transient ischemia. Stroke 39: 1569-1574. [PubMed]

72. Boltze J, Arnold A, Walczak P, Jolkkonen J, Cui L, et al. (2015) The Dark Side of the Force - Constraints and Complications of Cell Therapies for Stroke. Front Neurol 6: 155. [PubMed]

73. Bacigaluppi M, Hermann DM (2008) New targets of neuroprotection in ischemic stroke. Sci World J 8: 698-712. [PubMed]

74. Marioni RE, Shah S, McRae AF, Chen BH, Colicino E, et al. (2015) DNA methylation age of blood predicts all-cause mortality in later life. Genome Bio 16: 25. [PubMed]

75. Perna L, Zhang Y, Mons U, Holleczek B, Saum KU, et al. (2016) Epigenetic age acceleration predicts cancer, cardiovascular, and all-cause mortality in a German case cohort. Clin Epigenetics 8: 64

76. Jin K, Mao X, Xie L, Greenberg RB, Peng B, et al. (2010) Delayed transplantation of human neural precursor cells improves outcome from focal cerebral ischemia in aged rats. Aging Cell 9: 1076-1083. [PubMed]

77. Jin K, Xie L, Mao X, Greenberg MB, Moore A, et al. (2011) Effect of human neural precursor cell transplantation on endogenous neurogenesis after focal cerebral ischemia in the rat. Brain Res 1374: 56-62. [PubMed]

78. Balseanu AT, Buga AM, Catalin B, Wagner DC, Boltze J, et al. (2014) Multimodal approaches for regenerative stroke therapies: combination of granulocyte colony-stimulating factor with bone marrow mesenchymal stem cells is not superior to G-CSF alone. Front Aging Neurosci 6: 130. [PubMed]

79. Li ZM, Zhang ZT, Guo CJ, Geng FY, Qiang F, et al. (2013) Autologous bone marrow mononuclear cell implantation for intracerebral hemorrhage - a prospective clinical observation. Clin Neurol Neurosurg 115: 72-76. [PubMed]

80. Bhasin A, Srivastava MV, Mohanty S, Bhatia R, Kumaran SS, et al. (2013) Stem cell therapy: a clinical trial of stroke. Clin Neurol Neurosurg 115: 10031008. [PubMed]

81. Honmou O, Houkin K, Matsunaga T, Niitsu Y, Ishiai S, et al. (2011) Intravenous administration of auto serum-expanded autologous mesenchymal stem cells in stroke. Brain 134: 1790-1807. [PubMed]

82. Lee JS, Hong JM, Moon GJ, Lee PH, Ahn YH, et al. (2010) A long-term followup study of intravenous autologous mesenchymal stem cell transplantation in patients with ischemic stroke. Stem Cells 28: 1099-1106. [PubMed] 